This is an Accepted Manuscript of an article published by Taylor \& Francis in Work \& Stress 31(4): 395-420 on 30 May 2017, available online: http://www.tandfonline.com/10.1080/02678373.2017.1330835 http://dx.doi.org/10.1080/02678373.2017.1330835

\title{
Long-term profiles of work-related rumination associated with leadership, job demands, and exhaustion: a three-wave study
}

\author{
Kaisa Perko and Ulla Kinnunen \\ University of Tampere \\ Taru Feldt \\ University of Jyväskylä
}

\begin{abstract}
Author Note
Kaisa Perko (kaisa.perko@uta.fi, tel. +358-504908278) and Ulla Kinnunen (ulla.kinnunen@uta.fi), School of Social Sciences and Humanities, Psychology, FIN-33014 University of Tampere, Finland.

Taru Feldt (taru.feldt@psyka.jyu.fi), Department of Psychology, University of Jyväskylä, P.O. Box 35, FIN-40014 University of Jyväskylä, Finland.

Correspondence concerning this article should be addressed to Kaisa Perko, School of Social Sciences and Humanities, Psychology, FIN-33014 University of Tampere, Finland, tel. +358-504908278, E-mail: kaisa.perko@uta.fi

Acknowledgments: The research project "Rewarding and Sustainable Health-Promoting Leadership (Re-Su-Lead)" was financially supported by the Finnish Work Environment Fund under Grant 109398. Work by the first author was supported by the Finnish Work Environment Fund and the Emil Aaltonen Foundation. In addition, the authors are grateful to Professor Asko Tolvanen for valuable advice on the statistical analyses.
\end{abstract}




\begin{abstract}
This study extends on previous research regarding recovery from work stress by investigating the role of qualitative job demands and leadership in employees' work-related rumination (WRR). The long-term development of WRR was examined from a person-centred approach across 22 months. Drawing on the stressor-detachment framework and the conservation of resources theory, we investigated whether different WRR profiles could be understood in terms of levels of and changes in job demands (quantitative, cognitive, emotional), several aspects of supervisory leadership, and exhaustion that was expected to result from the impeded energy restoration process. A three-wave questionnaire study was conducted among Finnish municipal employees in heterogeneous occupations. Factor mixture modelling was used to identify latent classes (i.e. subgroups of participants with similar mean levels and mean level changes) of WRR. The results indicated five distinct classes of work-related rumination. Participants in the higher WRR classes reported higher levels of job demands, less supervisor fairness, and more abusive supervision. In the decreasing class, WRR decreased concurrently with decreasing job demands. Exhaustion showed considerable congruence with WRR both between and within persons. The findings are discussed from the point of view of a loss cycle concerning energetic psychological resources and difficulties in goal attainment.
\end{abstract}

Keywords: work-related rumination, perseverative cognition, leadership, job demands, exhaustion, recovery from work stress 


\section{PROFILES OF WORK-RELATED RUMINATION}

\section{Introduction}

Recovery from work is not always successful. One reason for this is that stressors of today's working life may not be easily left behind. After job-related activities have ended, mental processing related to work stressors can continue, prolonging psycho-physiological stress reactions and hindering recovery from work (Cropley \& Zijlstra, 2011; Geurts \& Sonnentag, 2006; Sonnentag \& Fritz, 2015). This study provides a long-term, person-centred perspective on perseverative, recurrent thoughts about job-related problems during off-job time, that is, workrelated rumination. By applying a person-centred approach, we aimed to yield results that are more easily interpretable at the single-individual level, compared to results from a variable-centred approach with focus on relationships between variables (Bergman \& Lundh, 2015; Bergman, Magnusson, \& El-Khouri, 2003; Laursen \& Hoff, 2006). In addition to identifying participants with similar developmental profiles of work-related rumination across a time span of two years, we investigated the extent to which the profiles can be understood in terms of job demands, leadership, and exhaustion.

The contribution of this study is three-fold. First, we extend the time frame of previous studies on work-related rumination from a few weeks to nearly two years. Second, we focus attention on leadership's role in employees' recovery and, in particular, work-related rumination. Although leaders are supposed to be in a crucial position to affect employees' psychological detachment from work (Sonnentag \& Fritz, 2015), little empirical knowledge on the topic exists. Third, utilizing a person-centred approach, we show how work-related rumination varies between and within individuals across time, and what is characteristic of individuals, for example, whose work-related rumination is chronically high, in terms of quantitative, cognitive, and emotional job demands, leadership, and development of exhaustion.

Instead of prediction, a strength of the person-centred approach is the identification and description of different types of individuals and their developmental profiles across time (Bergman \& Trost, 2006; Laursen \& Hoff, 2006). The person-centred approach can be described as holistic 


\section{PROFILES OF WORK-RELATED RUMINATION}

because of its emphasis that an array of related factors contribute to the same direction on the level of the individual (Bergman \& Trost, 2006). By examining absolute changes (mean values as opposed to the relative order of individuals) within naturally occurring subgroups of participants, we also respond to the call for more descriptive studies on change in the variables of interest (Kelloway \& Francis, 2013), and in particular, to the need to examine across-time development in mean levels related to resource gain and loss processes (Taris \& Kompier, 2014).

\section{Work-related rumination as a reaction to problems in goal attainment}

According to a classical definition, rumination refers to "a class of conscious and recurrent thoughts that revolve around a common instrumental theme and that recur in the absence of immediate environmental demands requiring the thoughts" (Martin \& Tesser, 1996, p. 7). Importantly, these thoughts are described as unintended and difficult to eliminate (Martin \& Tesser, 1996). In the current study, ruminative thoughts centre on work-related problems, and we examine these thoughts during off-job time when the individual is, in principle, free from work demands.

Ruminative thoughts emerge when there is a subjectively experienced discrepancy in goal progress, that is, when there are problems in progress towards the goal, but the goal is still maintained and not abandoned (Martin \& Tesser, 1996; see also Cropley \& Zijlstra, 2011). Goals can be broadly defined as internal representations of desired states of affairs (Austin \& Vancouver, 1996). At work, people have multiple important goals, most pertaining to accomplishment of work tasks or retaining social resources like social support from the supervisor (Halbesleben, 2006). However, not every little unattained goal will be ruminated upon. People ruminate primarily about goals that are perceived to be central to one's well-being, that is, higher order-goals, and only when there are hindrances in the way towards the desired state (Martin \& Tesser, 1996). Rumination understood in this way "is an attempt at problem solving - even when it isn't solving the problem" (Carver, 1996, p. 50). 
PROFILES OF WORK-RELATED RUMINATION

\section{Work-related rumination prolongs stress-related activation}

The perseverative cognition hypothesis states that psychosocial stressors contribute to ill health through perseverative cognitions (worry, ruminative thoughts, anticipatory stress) that prolong stress-related physiological activation (see Brosschot, Gerin, \& Thayer, 2006; Ottaviani et al., 2016, for reviews). Thus, at the core of work-related rumination, cognitive representations of work-related stressors prolong affective and physiological activation related to these stressors (Brosschot et al., 2006; Cropley, Rydstedt, Devereux, \& Middleton, 2015; Geurts \& Sonnentag, 2006). This prolonged psycho-physiological activation is also why the stressor-detachment model states that psychological detachment from work is a core recovery experience (Sonnentag \& Fritz, 2015).

In the literature on recovery from work stress, the concept of psychological detachment holds a central place (Sonnentag \& Fritz, 2015). Psychological detachment is described in terms of the absence of both job-related activities and any kind of job-related thoughts (Sonnentag \& Fritz, 2015). While the presence of job-related thoughts, and thereby lack of psychological detachment, may take many forms, work-related rumination refers to predominantly stressful or negative thoughts. This is because by definition, these thoughts are repetitive, unintentional, and difficult to control, that is, intrusive (Cropley et al., 2015).

In fact, increasing evidence reveals that positive work-related thoughts during off-job time, which also indicate a lack of psychological detachment, show beneficial effects (Flaxman, Ménard, Bond, \& Kinman, 2012; Fritz \& Sonnentag, 2005; Meier, Cho, \& Dumani, 2016). For example, a series of three diary studies demonstrated that positive work reflections predicted better affective well-being (Meier et al., 2016). Hence, it seems that the detrimental effects of low detachment are explained by job-related thoughts with particularly negative affective valence. Therefore, the stressor-detachment model seems to gain its relevance when the focus is on constructs like workrelated rumination, the crux of poor detachment (Sonnentag \& Fritz, 2015, p. S85). Accordingly, 


\section{PROFILES OF WORK-RELATED RUMINATION}

we contend that rumination is a particularly detrimental manifestation of poor psychological detachment because of the tone and perseverative nature of the thoughts and the prolonged activation related to them (Brosschot et al., 2006; Flaxman et al., 2012; Geurts \& Sonnentag, 2006).

The costs and consequences of inadequate recovery following effort investment in job demands has been elaborated in the effort-recovery model that combines aspects of physical and mental load (Meijman \& Mulder, 1998). According to this model, effort expenditure at work causes short-term psychophysiological load reactions, which are reversible in principle. When the load exposure ceases, recovery occurs, that is, the psycho-biological system stabilizes to pre-stressor levels. However, this process is hindered if work stressors are relived through work-related rumination. Due to the impeded recovery process, individuals need to raise their effort levels to meet the demands of the work (Meijman \& Mulder, 1998). This compensatory effort contributes to the accumulation of load reactions. Because of continued exposure to job demands and quantitatively and qualitatively insufficient recovery, short-term irreversible load reactions become more persistent and harmful (Meijman \& Mulder, 1998), and constitute risk factors for impaired health and organic diseases (Brosschot et al., 2006; Ottaviani et al., 2016). Regarding work-related rumination, there is some empirical support for prolonged psycho-physiological activation, as indicated by deviant patterns of cortisol secretion among high ruminators (Cropley et al., 2015).

\section{High job demands aggravate work-related rumination}

It has long been known that recovery from work is hindered by prolonged and intensive exposure to job demands (Geurts \& Sonnentag, 2006; Meijman \& Mulder, 1998). Considering literature on psychological detachment, a wide range of studies with various designs (e.g. withinperson, other-reports) have shown that difficulties in switching off from work are associated with demands at work (for reviews, see Sonnentag \& Fritz, 2015; Wendsche \& Lohmann-Haislah, 2017).

Of relevance to the current study, ruminative thoughts are posited to arise especially in situations when there is a mismatch between an individual's resources and environmental demands, 


\section{PROFILES OF WORK-RELATED RUMINATION}

that is, when a person experiences stress (Martin \& Tesser, 1996). In the occupational domain, this view is supported by a longitudinal between-person study on work stress (Van Laethem et al., 2015) and a within-person study on distressing works shifts (Radstaak et al., 2014) as predictors of workrelated perseverative cognitions (similar concept to broadly defined work-related rumination). In addition, time pressure has been shown to relate to increased work-related rumination both between and within persons (Berset, Elfering, Lüthy, Lüthi, \& Semmer, 2011; Syrek \& Antoni, 2014; Syrek, Weigelt, Peifer, \& Antoni, 2017). Similarly, high job strain (high demands accompanied by low control and low skill utilization) was related to rumination about work (Cropley \& Purvis, 2003). Thus, there is reason to assume that unfavourable work conditions and, particularly, quantitative job demands have an increasing impact on work-related rumination.

Considering the exact mechanisms through which job demands contribute to work-related rumination, recent studies (Smit \& Barber, 2016; Syrek et al., 2017) support the view that ruminative thoughts are triggered by unattained goals (Martin \& Tesser, 1996). When a work situation places more demands on employees, they have more to process, more goals to achieve, more unfinished tasks, and thereby more discrepancies in goal attainment (Smit \& Barber, 2016; Syrek et al., 2017; Syrek \& Antoni, 2014). One study utilized a work planning intervention and demonstrated how attentional shift from workload and uncompleted goals enhanced psychological detachment (Smit et al., 2016), thereby providing direct support for the rationale behind increased demands at work, unattained goals, and work-related rumination.

While previous studies have highlighted the role of quantitative job demands in work-related rumination (Berset et al., 2011; Querstret \& Cropley, 2012; Sonnentag \& Fritz, 2015; Syrek \& Antoni, 2014), much less is known about how other types of job demands relate to difficulties in switching off from work. Particularly emotional and cognitive demands may be difficult to leave aside as they are easily relived and processed after work hours (Sonnentag \& Fritz, 2015; Cropley \& Zijlstra, 2011). Although responding to these job demands is not necessarily stressful, the demands can turn into stressors if the employee has not recovered properly from previous effort 


\section{PROFILES OF WORK-RELATED RUMINATION}

(Bakker \& Demerouti, 2007; Meijman \& Mulder, 1998). Although empirical research to date is scarce on this topic, correlations reported in previous studies suggest that cognitive demands (e.g. decision making and concentration) and emotional demands (e.g. relating to other people's personal problems) also hinder psychological detachment (Kinnunen, Feldt, Siltaloppi, \& Sonnentag, 2011; Oosthuizen, Mostert, \& Koekemoer, 2011; Wendsche \& Lohmann-Haislah, 2017).

\section{Leadership as an antecedent to work-related rumination}

Despite the increasing body of research on leadership and employee well-being (for reviews, see Harms, Credé, Tynan, Leon, \& Jeung, 2017; Skakon, Nielsen, Borg, \& Guzman, 2010), there is a gap in the literature regarding the role of leadership in facilitating or hindering employees' recovery process. Consequently, in this study we investigated four leadership behaviours: transformational leadership, supervisor fairness, conflict management, and abusive supervision. Based on the accumulated research, transformational leadership, supervisor fairness, and conflict management can be conceived as resourceful social aspects of the job that support goal attainment and wellbeing among employees (Bakker \& Demerouti, 2007), whereas abusive supervision constitutes a stressor (Harms et al., 2017; Schyns \& Schilling, 2013).

Of the leadership behaviours mentioned above, transformational leadership has received research attention in relation to work-related rumination. Transformational leadership refers to inspirational, visionary leaders who convey a higher purpose of the work to followers, which serves the intrinsic needs of followers and motivates them (Bass, 1985; Judge \& Piccolo, 2004). High levels of transformational leadership were found to relate to low levels of work-related rumination (Perko, Kinnunen, \& Feldt, 2014) and to alleviate the detrimental effects of time pressure on worklife balance and exhaustion (Syrek, Apostel, \& Antoni, 2013). Thus, transformational leadership may facilitate switching off from work and turning to the non-work sphere of life. However, leaders' high performance expectations, an attribute inherent in transformational leadership theory (Bass, 1985), may aggravate rumination. In a diary study, unfinished work tasks at the end of a 


\section{PROFILES OF WORK-RELATED RUMINATION}

working week were found to increase work-related rumination and impair sleep quality; both relationships were strengthened by supervisors' high performance expectations, as appraised by employees (Syrek \& Antoni, 2014).

Furthermore, supervisory leaders low in the organizational hierarchy—the targets of employee ratings in our study_-are likely to have limited possibilities of influence through all aspects of transformational leadership (Alimo-Metcalfe, 2013). Considering this, in the present study, we consider leadership behaviours that are essential in daily supervisory work, but that have received inadequate attention in research, namely taking an active role to resolve social conflicts among employees and fair (just) supervisor behaviours (fair distribution of work and equal treatment of employees). Regarding conflict management, findings from previous studies indicate that employee strain (e.g. sleep disturbances, exhaustion) is lower when supervisors employ an active, collaborative, and discussing style in settling conflicts in work units instead of, for example, being avoidant or authoritatively forceful (Hyde, Jäppinen, Theorell, \& Oxenstierna, 2006; Montano, 2016; Way, Jimmieson, \& Bordia, 2014).

In addition, we examine abusive supervision as an indicator of unfavourable behaviours. In contrast to resourceful forms of leadership, abusive supervision, referring to subordinates' perception of a "sustained display of hostile verbal and nonverbal behaviours, excluding physical contact" (Tepper, 2000, p. 178), can be considered a job-related demand (Bakker \& Demerouti, 2007). Disrespectful treatment by a supervisor requires sustained psychological effort on the part of an employee and has, consequently, psychological costs (Tepper, 2000), for which there is metaanalytic support (Harms et al., 2017; Schyns \& Schilling, 2013).

Experience of injustice may explain employee reactions to both low-level supervisor fairness and abusive supervision (Tepper, 2000). Abusive and unfair supervisor behaviours are particularly likely to instigate ruminative thoughts because of the stress-producing experience of threat that is involved in perceptions of injustice (Ford \& Huang, 2014). In general, the importance of justice (fairness) of organizational authorities is underpinned by the vast organizational justice literature 


\section{PROFILES OF WORK-RELATED RUMINATION}

(Colquitt et al., 2013). With specific regard to employee well-being, findings of a meta-analysis showed that unfairness (injustice, albeit typically measured as low justice) of immediate supervisors explains employee strain such as burnout particularly well (Robbins, Ford, \& Tetrick, 2012). The impact of unfair leadership on employee health and well-being is arguably mediated by stressful thoughts as exemplified by work-related rumination (Brosschot et al., 2006). Therefore, less than optimal levels of supervisor fairness, as well as abusive supervision, may increase work-related rumination.

In support of these, to our knowledge, unexplored associations, two daily diary studies examined within-person effects of mistreatment (social conflicts) in the workplace on employee reactions after the workday. Mistreatment by a supervisor predicted negative affective states at bedtime among subordinates (Volmer, 2015) and, similarly, mistreatment by customers predicted rumination during the night and negative mood the next morning (Wang et al., 2013). Thus, there is empirical evidence that social mistreatment increases work-related rumination. We propose, accordingly, that sustained exposure to unfairness and hostility from a supervisor shows similar effects.

\section{Exhaustion as an outcome of work-related rumination}

A significant number of recovery studies have demonstrated a lack of psychological detachment to relate to increased strain reactions, consistent with the stressor-detachment model (for a review, see Sonnentag and Fritz, 2015). In this study, we examined exhaustion as an indicator of strain to which work-related rumination may lead in the long term. Emotional exhaustion, the core component of occupational burnout, refers to "feelings of being overextended and depleted of one's emotional and physical resources" (Maslach et al., 2001, p. 399), that is, feelings of tiredness and lack of energy. Given that psychophysiological energy enables proper functioning at work, it is a major resource in a work setting (e.g. Zijlstra, Cropley, \& Rydstedt, 2014; Zohar, Tzischinski, \& Epstein, 2003). Essentially, recovery can be conceived as the restoration of energy resources 


\section{PROFILES OF WORK-RELATED RUMINATION}

(Zijlstra et al., 2014) that are needed for exerting mental and physical effort (Meijman \& Mulder, 1998). In support of the exhausting influence of work-related ruminative thoughts, work-related worry and rumination during a respite from work predicted an increase in exhaustion afterwards in a study among academics (Flaxman et al., 2012).

According to the conservation of resources theory (COR; Hobfoll, 1989, 2001), resource loss is the primary component in the stress process. The basic tenet of the COR theory is that people strive to obtain, retain, protect, and build entities that are valued (i.e. resources) and potential or actual loss of these valued resources causes psychological stress (Hobfoll, 1989). Resource loss makes people vulnerable to further losses, particularly if they lack resources that would be needed to offset additional losses (Hobfoll, 1989). Thus, the role of resources becomes salient in times of loss when there is a risk for a loss cycle (Hobfoll, 2001). Of relevance to the recovery perspective, stress occurs if individuals fail to gain resources after significant resource investment (Hobfoll, 1989). This is compatible with the notion of exhaustion resulting from impeded recovery after investment of effort in job demands. As for longitudinal evidence, poor psychological detachment predicted an increase in emotional exhaustion within one year (Sonnentag, Binnewies, \& Mojza, 2010). Similarly, sustained cognitive activation in the form of preoccupation with thoughts of work during leisure time predicted clinical burnout across two years while controlling for job demands (Söderström, Jeding, Ekstedt, Perski, \& Åkerstedt, 2012).

\section{The present study}

Overall, the purpose of the present study was to gain understanding of the long-term development of work-related rumination from a person-centred view. Thus, we aimed to show how job demands, leadership, and exhaustion are experienced by individuals with different long-term profiles of work-related rumination. For this purpose, we utilized models of mental presence of stressors (Brosschot et al., 2006; Sonnentag \& Fritz, 2015; Geurts \& Sonnentag, 2006) and their impeding effect on recovery as understood in the E-R model (Meijman \& Mulder, 1998). In 


\section{PROFILES OF WORK-RELATED RUMINATION}

addition, the COR theory principles (Hobfoll, 1989) were utilized to conceive effort expenditure at work as energy investment and recovery as restoration of energy resources (Zijlstra et al., 2014).

Specifically, this study had three goals. First, we aimed to identify latent classes (a priori unknown subgroups) of participants who were similar within classes and different between classes with respect to the development of work-related rumination (WRR). Second, we investigated what was typical for participants in the different WRR classes regarding job demands and leadership across time. Third, we examined how the varying WRR profiles differed across time in exhaustion. Particularly the first goal, concerning the identification of latent classes, was explorative and thereby incompatible with the formation of exact hypotheses, and the two latter goals depended on the first goal. Therefore, we posed only general hypotheses.

Regarding the second goal on job demands and leadership as antecedents of work-related rumination, we hypothesized that employees high in work-related rumination would show generally higher levels of quantitative, cognitive, and emotional job demands compared to employees whose work-related rumination was low (Hypothesis 1). Expanding on the second goal, we expected that employees low in work-related rumination would display a favourable pattern of leadership behaviours (Hypothesis 2). In other words, leadership behaviours categorized as job resources (transformational leadership, supervisor fairness, conflict management) would be higher and abusive supervision would be lower in comparison to employees with higher levels of work-related rumination. Concerning exhaustion resulting from work-related rumination (goal 3), we built on the idea that energy levels would decline in the long term if the process of energy restoration (recovery) was impeded by work-related rumination (Hobfoll, 1989; Meijman \& Mulder, 1998; Zijlstra et al., 2014). We therefore expected that employees demonstrating constantly high levels of work-related rumination would show particularly high levels of exhaustion (Hypothesis 3). 


\section{PROFILES OF WORK-RELATED RUMINATION}

\section{Methods}

\section{Participants and procedure}

This study was part of a larger research project [name removed for anonymous review] focusing on leadership and employee well-being. A questionnaire study consisting of three measurement waves was conducted across an average total time span of 22 months. Participants in the present study were 625 municipal employees from various occupations in four Finnish cities. The cities' human resources staff recruited work units to participate in the study. We used both online and postal questionnaires to gather data, as not all employees had work e-mail addresses and access to computers at work. The questionnaires were accompanied by a letter stating that participation was voluntary and confidential. The first wave (T1) data were collected in the early spring of 2011, the second wave (T2) about 14 months later in the late spring of 2012, and the third wave (T3) in the early 2013, about 8 months after T2. These time lags were mainly determined based on the schedule of an intervention that was conducted in other countries participating in the project. The response rate at baseline was $62.5 \%$ (for details of the $\mathrm{T} 1$ sample and participant recruitment, see Perko et al., 2014). Of the T1 participants, $47.2 \%$ continued participation at T2. At T2, new employees were eligible to participate in the study (71 new employees entered) and nonrespondents from $\mathrm{T} 1$ were re-invited to participate, yielding a response rate of $36.2 \%$. At T3, questionnaires were sent only to former participants and $52.9 \%$ responded.

In the present study, we included all the participants who completed one $(n=258)$ or several ( $n=367)$ of the consecutive three questionnaires and who stayed in a subordinate position across the study period. Hence, the sample size varied between the measurement waves (at $\mathrm{T} 1, N=554$, at $\mathrm{T} 2, N=333$, and at T3, $N=294)$. Regarding longitudinal participation, 262, 225, and 258 employees responded at both $\mathrm{T} 1$ and $\mathrm{T} 2$, both $\mathrm{T} 2$ and $\mathrm{T} 3$, and both $\mathrm{T} 1$ and $\mathrm{T} 3$, respectively. One hundred and eighty-nine employees responded across all three waves. 


\section{PROFILES OF WORK-RELATED RUMINATION}

The 625 participants $(N=554$ at $\mathrm{T} 1$ increased by 71 new participants at T2) worked in diverse occupations, including child care $(21.1 \%)$, teaching (20.6\%), cleaning (19.5\%), catering $(11.5 \%)$, property maintenance $(7.4 \%)$, nursing and assistance $(7.0 \%)$, and others $(12.9 \%)$ such as secretary, administrative, and social work. Women comprised most of the participants $(85.0 \%)$. The mean age was $48.7(S D=10.0)$, and age range was $21-66$ years. Participants were from a range of educational backgrounds. The highest level of education completed was comprehensive school for $11.6 \%$ of participants, vocational qualifications or matriculation examination for $43.3 \%$, a bachelor's degree or equivalent for $21.8 \%$, and $23.4 \%$ of the participants had (at least) a master's degree or equivalent. Considering T1 participants, almost all (94.7\%) had a permanent work contract as opposed to a temporary one $(5.3 \%)$.

\section{Measures}

All measures were assessed in the three waves and showed acceptable internal consistencies (Cronbach's $\alpha$ ).

Work-related rumination was assessed with the following three items (translated from the original German 3-item measure on cognitive irritation): "I have difficulty relaxing after work", "Even at home I often have to think about my problems at work", and "Even on holiday I sometimes must think about my problems at work" (Mohr, Müller, Rigotti, Aycan, \& Tschan, 2006). Responses were given on a Likert-type scale from 1 (strongly disagree) to 7 (strongly agree). Cronbach's $\alpha$ calculated for each measurement wave varied from .77 to .81 .

Job demands. Workload was assessed with the 5-item Quantitative Workload Inventory (Spector \& Jex, 1998) that measures the amount of work in terms of pace and volume (e.g. "How often does your job leave you with little time to get things done?"). Responses were given on a scale from 1 (very seldom or never) to 5 (very often or always). Cronbach's $\alpha$ was .83 at all measurement points. Cognitive demands were measured with the 4-item scale (e.g. "Does your work require you to make complex decisions?") from the Copenhagen Psychosocial Questionnaire 


\section{PROFILES OF WORK-RELATED RUMINATION}

(COPSOQ II; Pejtersen, Kristensen, Borg, \& Bjorner, 2010). The rating scale ranged from 1 (very seldom or never) to 5 (very often or always). Cronbach's $\alpha$ varied from .84 to .85 . Emotional demands were likewise assessed with the 4-item scale (e.g. "Does your work put you in emotionally disturbing situations?”) from the COPSOQ II (Pejtersen et al., 2010). For two items, the rating scale ranged from 1 (very seldom or never) to 5 (very often or always), and for two other items, from 1 (to a very small extent) to 5 (to a very large extent). Cronbach's $\alpha$ varied between .84 and .86 .

Leadership. Transformational leadership was measured with the Global Transformational Leadership Scale (Carless, Wearing, \& Mann, 2000) comprising seven items (e.g. "My immediate superior instils pride and respect in others and inspires me by being highly competent"). The rating scale varied from 1 (to a very small extent) to 5 (to a very large extent). Cronbach's $\alpha$ ranged from .90 to .91. Supervisor fairness was measured with two fairness-specific items ("Does your immediate superior treat the workers fairly and equally?" and "Does your immediate superior distribute the work fairly and impartially?") from the 3-item fair leadership scale in the QPS Nordic questionnaire (Dallner et al., 2000). The third item of the original scale concerned a stressful relationship between the supervisor and the employee and was not measured in this study because it was unspecific with regard to fairness. Further, the omitted item showed a low loading (-.42) on the factor of supervisor fairness in the validation study (Dallner et al., 2000). Responses were given on a scale from 1 (very seldom or never) to 5 (very often or always). Correlations of the two items varied between .79 and .86. Conflict management was assessed with a 3-item conflict management subscale from the health-promoting leadership scale (Vincent, 2012). The items (e.g. "My immediate superior searches for solutions to conflicts with those involved") were rated on a scale from 1 (strongly disagree) to 5 (strongly disagree). Cronbach's $\alpha$ varied from .79 to .80. Abusive supervision was measured with the shortened abusive supervision scale (Mitchell \& Ambrose, 2007; Tepper, 2000) consisting of five items on active abuse (e.g. "My nearest superior puts me 


\section{PROFILES OF WORK-RELATED RUMINATION}

down in front of others"). The rating scale varied from 1 (strongly disagree) to 7 (strongly agree). Cronbach's $\alpha$ ranged between .90 and .92 .

Exhaustion was measured with three items (e.g. "I feel burned out from my work") from the 5-item exhaustion subscale of the Finnish version of Maslach Burnout Inventory (Kalimo, Hakanen, \& Toppinen-Tanner, 2006). Responses were given on a scale from 0 (never) to 6 (every day). Cronbach's $\alpha$ varied from .82 to .85 .

Background factors. We additionally examined whether the latent classes differed in age, gender, and education level. Higher education has been found to relate to higher work-related rumination in population-based samples (Cropley \& Zijlstra, 2011; Van Laethem et al., 2015). Furthermore, we were able to examine whether changes in perceived leadership were explained by replacement of the person being rated between the measurement times.

Correlations between the study variables are presented in Table 1. Cross-sectional correlations are presented at T1, when the sample size was largest, and longitudinal correlations are shown for the lengthiest time lag, T1-T3.

\section{Attrition analyses}

As reported previously (Perko et al., 2014), there were slightly more women among the respondents at $\mathrm{T} 1$ as compared to the population in the work units (85\% vs. 81\%). Respondents who continued participation at T2 $(n=262)$ did not differ from those who discontinued participation $(n=292)$ at T2 with respect to their ratings in any of the study variables at T1, or in gender or age (Perko, Kinnunen, Tolvanen, \& Feldt, 2016). Concerning attrition between T2 and T3, participants who dropped out at T3 $(n=108)$ reported higher levels of exhaustion at T2 $(M=$ 2.48 vs. $M=1.93), U=8924.50, p<.001$ than those who continued participation at T3 $(n=225)$. There were no differences in other study variables, gender, or education level, but those who continued participation at T3 were slightly older $(M=49.36$ vs. $M=46.77)$ than those who discontinued after $\mathrm{T} 2, t(173.23)=-2.11, p=.036$. Concerning attrition between $\mathrm{T} 1$ and $\mathrm{T} 3$, we 


\section{PROFILES OF WORK-RELATED RUMINATION}

found that respondents $(n=258)$ reported slightly more favourable values in transformational leadership $(M=3.23$ vs. $M=3.05), t(544.91)=-2.38, p=.018$ and conflict management $(M=3.87$ vs. $M=3.60), U=43536.00, p=.001)$ than did drop-outs $(n=296)$. With respect to background variables, respondents at T3 were older $(M=49.19$ vs. $M=47.34), t(539.02)=-2.26, p=.025$. than non-respondents. Additionally, sample attrition between T1-T3 can be partly due to actual turnover, as drop-outs (7.8\%) more often than respondents at T3 (2.4\%) had a fixed-term work contract, $\chi^{2}(1)$ $=8.06, p=.005$.

To summarize, women and older employees were somewhat more active to take part in the study than men and younger employees. Regarding the study variables, we concluded that the data were somewhat biased because of sample attrition. Due to attrition, specifically at T3, the highest levels in exhaustion and lowest levels in transformational leadership and conflict management were underrepresented in the sample used.

\section{Statistical analyses}

The analysis comprised a person- and variable-centred phase. First, factor mixture modelling (Lubke \& Muthén, 2005) was used to identify latent classes of participants across the three measurement points based on sum scores of work-related rumination. Latent classes refer to latent subpopulations in the data not known beforehand but that can be analysed with various mixture modelling techniques (Lubke \& Muthén, 2005). The factor mixture analysis was performed with Mplus (version 7.3, Muthén \& Muthén 1998-2012). The method of estimation was maximum likelihood with robust standard errors (MLR). Missing data were handled through full information maximum likelihood (FIML), which enables the use of all available information without imputing values (Little, 2013). Thus, all participants who responded in any of the measurement waves could be included.

In the factor mixture analysis, covariance of observed variables within classes was modelled through a common factor that captured individual variation in the level of work-related rumination 


\section{PROFILES OF WORK-RELATED RUMINATION}

across time (Lubke \& Muthén, 2005). The intercept of the level factor was fixed to zero in the overall part of the model, and class-specific mean values (indicators of the latent level factor) were estimated. Acknowledging the limitations of our incomplete longitudinal data, this parsimonious model successfully served our aim to capture all mean-level change in work-related rumination that occurred in each latent class. Further, multiple statistical criteria were used to determine the final number of classes (Nylund, Asparouhov, \& Muthén, 2007, see Table 2). In addition, selection of the final model was based on the substantive meaningfulness and interpretability of the solution as well as the stability of a given class across the solutions (Lubke \& Muthén, 2005). After the latent class solution was determined, we additionally tested whether changes in work-related rumination (model variable) within the classes were significant using Wald's test in Mplus.

Second, job demands, leadership and exhaustion were compared between the classes as distal observed variables, that is, variables outside the latent class model (Asparouhov \& Muthén, 2014). These analyses were performed considering the uncertainty related to group membership by using posterior probabilities and thereby treating the latent class variable as a latent and not observed variable. For this purpose, we used the automatic $\mathrm{BCH}$ method as implemented in Mplus (Asparouhov \& Muthén, 2014). This method has been shown to best preserve the original latent class solution when comparing distal variables, and performs well even if the variances of distal variables vary substantially across classes. The procedure yields overall results on differences in mean values between classes based on the Wald's chi-square test and additionally pairwise comparisons. We compared job demands, leadership, and exhaustion between the latent classes at the beginning (T1, $N=554)$ and end of the study period $(\mathrm{T} 3, N=294)$.

To examine changes within classes, we calculated change scores for the distal variables. First, utilizing the most likely latent class, change scores were calculated (in SPSS) by subtracting the mean value of the distal variable at an earlier time point from its mean value at the later time point (e.g. T3 mean-T1 mean). Thus, negative values indicated a decrease and positive values indicated an increase in the distal variable. Importantly, the change scores were then re-estimated within the 


\section{PROFILES OF WORK-RELATED RUMINATION}

latent classes using posterior probabilities as the basis for the latent classes. To determine whether change was significant, we calculated Student's $t$-test results (degrees of freedom $n-1$ based on the mostly likely latent class). Altogether, development of distal variables was investigated in all three time lags, that is, T1-T2 $(n=262), \mathrm{T} 2-\mathrm{T} 3(n=225)$, and T1-T3 $(n=258)$. These analyses comprised only those participants in the incomplete longitudinal data who had participated at both measurement times in question.

\section{Results}

\section{Identifying latent classes of work-related rumination}

The fit indices and class sizes of alternate class solutions in the factor mixture analysis are presented in Table 2. Among the varying statistical criteria, we relied primarily on BIC and BLRT as these indicators have performed well in simulation studies (Nylund et al., 2007; Tolvanen, 2007). In a comparison of the models, BIC suggested the five-class solution fit the data best. BLRT indicated that the fit of the five-class solution was significantly $(p<.001)$ better than the fit of the four-class solution, and further, that the six-class solution fit significantly $(p=.010)$ better than the five-class solution. The solutions for five and six classes were carefully compared after which we selected the five-class solution as the final model. This decision was based on parsimony in modelling and the low added substantive value of another small increasing pattern $(n=4)$ in the six-class model. The average probabilities for the most likely latent-class membership varied between .727 and .895 , thereby indicating acceptable clarity of classification.

The five classes demonstrated low, increasing, decreasing, high, and moderate profiles of work-related rumination, and were labelled accordingly. The model-based mean values of workrelated rumination within each class are shown in Table 3. The largest and thereby most typical latent class, Low, consisted of participants who remained constantly low in work-related rumination (with overall class counts based on posterior probabilities $n=291,46.7 \%$ ). Despite staying low in all time frames examined, the Low class showed a slight increase in work-related rumination in T1- 


\section{PROFILES OF WORK-RELATED RUMINATION}

T2 $(p=.013)$. Salient change patterns in work-related rumination occurred in the Increasing $(n=$ $36,5.8 \%)$ and Decreasing $(n=65,10.4 \%)$ classes, in which the same change trend continued from T1-T2 further to T2-T3. The changes in these classes were significant $(p<.001)$ for all three time frames (except the Increasing class T1-T2, $<<.01$, and Decreasing class T2-T3,p<.05). These change classes jointly formed a $16.2 \%$ minority of the participants. Also, constantly High workrelated rumination $(n=77,12.5 \%)$ was atypical. In the High class, there was a slight decrease in work-related rumination in T1-T2 $(p=.022)$ that a decrease in T1-T3 $(p=.032)$ also reflected. In the Moderate class the participants repeatedly reported work-related rumination above the sample means $(n=154,24.7 \%)$, but the ratings remained lower than those of the High class. The Moderate class was the most stable without any significant changes in work-related rumination. In sum, low and moderate levels of work-related rumination were more typical than constantly high or predominantly changing levels.

\section{Differences in job demands, leadership, and exhaustion between latent classes}

\section{Job demands}

As seen in Table 3, the overall test results for differences between the latent classes showed that the WRR classes differed for all job demands both at T1 and T3. Pairwise comparisons showed that the participants in the higher WRR classes consistently reported higher job demands than the participants in the lower WRR classes. Comparing types of job demands, the differences were particularly salient for emotional job demands.

\section{Leadership}

At T1, the WRR classes differed in all leadership behaviours with participants in the Low and Decreasing WRR class mostly reporting more favourable leadership behaviours than the Moderate and High WRR classes. Differences were strongest in supervisor fairness and abusive supervision, which were also the only leadership behaviours showing significant differences between the WRR classes at T3 (Table 3). 


\section{PROFILES OF WORK-RELATED RUMINATION}

\section{Exhaustion}

There were particularly salient differences between the WRR classes in exhaustion both at T1 and T3. Pairwise comparisons showed that these differences were in accordance with the levels of work-related rumination, concerning also the Increasing and Decreasing WRR classes (Table 3).

\section{Changes in job demands, leadership, and exhaustion within the latent classes}

Table 4 shows change scores for job demands, leadership, and exhaustion within the latent classes in T1-T3 (the number of participants in each class and time lag can be seen below the table).

\section{Job demands}

As seen in Table 4, the Decreasing class showed a significant decrease in all job demands between $\mathrm{T} 1$ and T3, that is, in workload, cognitive demands, and emotional demands. The increase in cognitive demands in the Low class and the increase in emotional demands in the Moderate class were also significant in T1-T3. Considering the study period divided in two shorter time lags (T1$\mathrm{T} 2$ and T2-T3), cognitive demands increased in the Low class T1-T2 (change $M=0.22, p<.001$, $S E=.06)$ in accordance with slightly increasing work-related rumination. Moreover, there were some significant short-term changes in job demands that occurred in classes that showed no significant change in work-related rumination in the time frame in question: workload decreased in the Low class in T2-T3 (change $M=-0.14, p<.05, S E=.06$ ) while emotional demands increased in the Moderate class in T1-T2 (change $M=0.35, p<.05, S E=.15$ ) and in the High class in T2T3 (change $M=0.36, p<.05, S E=.17$ ).

\section{Leadership}

Leadership was considerably more stable within the WRR classes as compared to job demands. However, transformational leadership and abusive supervision showed significant changes within the classes. In T1-T3, transformational leadership increased in the Low class (Table 4). Specifically, in the Increasing WRR class, that showed increases in work-related rumination, abusive supervision increased in TI-T2 (change $M=0.28, p<.05, S E=.12$ ) and transformational 


\section{PROFILES OF WORK-RELATED RUMINATION}

leadership decreased in T2-T3 (change $M=0.22, p<.05, S E=.09$ ). The significant decrease in transformational leadership in T2-T3 occurred independent of an actual change of the target leader, because in T2-T3, none of the participants in the Increasing class changed their leader across time. In T1-T2, after excluding two participants whose leader changed, the change in abusive supervision did not remain significant. It is noteworthy that $58.8 \%(n=10)$ of the participants in the Increasing class did not face abusive supervision at all (responded "strongly disagree" to all items), which is only slightly lower than the proportion in the sample as a whole, $66.5 \%$ at T1. Concerning the Low class, a closer inspection revealed that the increase in transformational leadership in T1-T3 was significant only among those 23 participants who rated a different leader at $\mathrm{T} 1$ as compared to $\mathrm{T} 3$. Thus, for some participants, a change of leader possibly contributed to a change in leadership ratings.

\section{Exhaustion}

In T1-T3, exhaustion increased significantly in the Increasing class and decreased significantly in the Decreasing class (Table 4). Similar changes were found in T1-T2 for the Increasing class ( $M=$ $1.05, p<.01, S E=.32)$ and Decreasing class $(M=-1.12, p<.01, S E=.35)$. There were no significant changes in exhaustion in T2-T3.

\section{Background factors between the latent classes}

Using posterior probabilities in Mplus, significant differences were found in age: $\chi^{2}(4)=11.52, p=$

.012 , gender: $\chi^{2}(4)=108.93, p<.001$, and level of education: $\chi^{2}(4)=44.69, p<.001$. Specifically, participants in the High WRR class were somewhat younger $(M=45.60, S E=1.37)$ than participants in the Low $(M=49.35, S E=0.66)$ and Increasing WRR classes $(M=53.09, S D=$ 2.20). Regarding education, participants with higher education were overrepresented in the High and Moderate WRR classes as compared to the Low WRR class $(p<.001)$. Concerning gender, the Increasing class differed from all other classes because it included disproportionally more women. 


\section{PROFILES OF WORK-RELATED RUMINATION}

\section{Discussion}

This longitudinal study investigated the development of work-related rumination from a personcentred perspective (Bergman et al., 2003; Bergman \& Trost, 2006). Accordingly, the core contribution of this study is the description of divergent long-term profiles of work-related rumination and how individuals with different WRR profiles meaningfully differ in job demands, leadership, and exhaustion.

\section{Long-term profiles of work-related rumination}

Concerning the first goal of the study, five latent classes displaying different profiles of workrelated rumination were identified. The participants in these classes demonstrated Low (46.7\%), Moderate (24.7\%), High (12.5\%), Increasing (5.8\%) and Decreasing (10.4\%) levels of workrelated rumination. Only the small Increasing and Decreasing WRR classes showed clear change trends that continued throughout the study period of nearly two years.

The second and third goal of this study pertained to characteristics of the latent WRR classes that were theoretically considered as antecedents and consequences for work-related rumination. The three generally formulated hypotheses on job demands, leadership, and exhaustion mainly gained support from our results. More specifically, Hypothesis 1 received strong support, as participants in the higher WRR classes consistently reported higher levels of job demands than participants in the lower WRR classes. This was noticeable also in the Decreasing WRR class, in which the participants across nearly two years reported decreases in workload, cognitive demands, and emotional demands in accordance with constant decreases in work-related rumination. Furthermore, supporting Hypothesis 2, the participants in the lower WRR classes reported more favourable leadership behaviours than participants in the higher WRR classes. In particular, the Low WRR class reported more supervisor fairness and conflict management, accompanied by less abusive supervision than did participants in the High and Moderate WRR classes. 


\section{PROFILES OF WORK-RELATED RUMINATION}

Regarding the third aim of the study and consistent with Hypothesis 3, participants in the classes that reported chronically high work-related rumination, especially the High WRR class, indicated higher exhaustion levels than did participants in other classes. In addition, particularly the Increasing and Decreasing class demonstrated changes in exhaustion that were fully congruent with their changes in work-related rumination. Altogether, the results revealed a notably close connection between exhaustion and work-related rumination at the person level. Implications of the results are next discussed in more detail.

\section{Theoretical contributions}

\section{Job demands and leadership}

Our findings concerning job demands are consistent with the stressor-detachment model, stating that job demands make it more difficult to disengage from work (Sonnentag \& Fritz, 2015), as well as previous variable-oriented findings specifically on the positive relationship between job demands and work-related rumination (Berset et al., 2011; Cropley \& Purvis, 2003; Querstret \& Cropley, 2012; Syrek \& Antoni, 2014). While previous studies have mainly examined quantitative job demands, in this study we found that cognitive and particularly emotional demands showed salient differences between the WRR classes. In addition, findings on decreasing job demands in the Decreasing WRR class support these notions. Thus, specifically, some emotional aspects of work are involved in the induction of rumination. This finding is in line with previous studies showing that demanding emotional events at work increase rumination (Wang et al., 2013) and, more generally, that especially emotional job demands along with work pressure interfered with individuals' functioning in various non-work roles (Oosthuizen et al., 2011).

Our result that participants in the higher WRR classes were more highly educated than participants in lower WRR classes is in accordance with previous findings indicating that perseverant work-related thoughts are more prevalent in higher socio-economic groups (Cropley \& Zijlstra, 2011; Van Laethem et al., 2015). These results highlight that the type of job matters in the 


\section{PROFILES OF WORK-RELATED RUMINATION}

propensity for work-related rumination, as individuals in higher socio-economic groups are likely to possess a more complex job. It seems that the more the job requires making complex decisions, remembering, and coming up with new ideas, information processing may easily continue after work hours in an employee's mind, even when not deliberately engaging in those thought processes.

Considering the potentially detrimental role of job demands, job-related resources are relevant as they counterbalance the effects of high job demands (Bakker \& Demerouti, 2007; Hobfoll, 2001; Wang et al., 2013; Volmer, 2015). Elaborating the role of job resources, it has been shown that the exhausting effect of emotional job demands can be mitigated by emotional support from supervisors and colleagues (de Jonge, Le Blanc, Peeters, \& Noordam, 2008). In the current study, we expected and found that work-related rumination was particularly high among employees reporting high job demands and low resources in leadership. Thus, participants reporting the highest levels of emotional job demands and work-related rumination seemed to lack the buffering resources in leadership.

Comparing leadership behaviours, the WRR classes differed especially in supervisor fairness along with abusive supervision. Thus, supervisor fairness, concerning respectful, equal treatment and fair distribution of work, appears to be the most efficient aspect of leadership with regard to preventing work-related rumination. Both abusive supervision and supervisor fairness centre around respect in employee treatment, which has been dealt with as interpersonal justice in the organizational justice literature (Colquitt et al., 2013; Ford \& Huang, 2014). Also, considering unfairness and abusive behaviours, it is clear that these types of leadership behaviours more easily turn into real stressors, as compared to mere deficiencies in implementing more resourceful aspects of leadership. In sum, the finding that elevated levels of work-related rumination are associated with breaches of justice in leadership is consistent with organizational justice literature conceiving supervisors as organizational authorities whose justice behaviours are highly influential in terms of strain among employees (Colquitt et al., 2013; Robbins et al., 2012). 


\section{PROFILES OF WORK-RELATED RUMINATION}

In general, leadership behaviours were considerably more stable within the WRR classes than job demands. This clearly reflects the fact that most of the participants rated the same leader across time, and the style and behaviours of individual leaders are stable across time to a relatively high degree. Altogether, changes within classes were found only for transformational leadership and abusive supervision. Although these changes could be partly attributed to change of the person being rated, particularly the results concerning the Increasing class leave open the question of whether only the employee perceptions changed or the same leader actually changed his or her behaviours. Considering both transformational leadership and abusive supervision, these leadership constructs can be seen to involve more affective content than the other constructs. A body of knowledge indicates that in addition to actual leader behaviours, various forms of employee affect are influential in employees' leadership ratings (e.g. Brown \& Keeping, 2005; Hansbrough, Lord, \& Schyns, 2015).

Although the participants in the Decreasing class showed no changes in leadership, it is important to note, however, that they initially reported lower emotional demands, more supervisor fairness, and conflict management, and less abusive supervision than did the participants who were constantly high in work-related rumination. Thus, these factors seem to facilitate favourable change in work-related rumination.

\section{Exhaustion and the profiles of work-related rumination}

Our results revealed a particularly consistent and strong connection between work-related rumination and exhaustion, which pertained to both differences between persons and changes within persons. This association as such is consistent with previous findings from variable-oriented studies (Flaxman et al., 2012; Querstret \& Cropley, 2012) and compatible with the notion of energy deficiency resulting from a disrupted recovery process (Sonnentag \& Fritz, 2015; Zijlstra et al., 2014). However, without the person-centred approach, we would not know that precisely the same participants who report increasing and decreasing work-related rumination, also display concurrent, corresponding changes in exhaustion. Although it is reasonable to assume that work-related 


\section{PROFILES OF WORK-RELATED RUMINATION}

rumination impedes the recovery process and thereby contributes to exhaustion (Geurts \& Sonnentag, 2006; Sonnentag \& Fritz, 2015), the finding of such a close connection between ruminative thoughts and energy deficiency evidently calls for deeper understanding of the relationship at the level of the individual.

In this regard, it is very interesting to note that also other types of studies have produced results that point to congruence. First, in a quasi-experimental study, rumination and fatigue decreased simultaneously after a cognitive-behavioural intervention on work-related rumination (Querstret, Cropley, Kruger, \& Heron, 2016). Second, longitudinal variable-centred studies have found not only that poor psychological detachment predicts exhaustion (Sonnentag et al., 2010), but also that exhaustion predicts poor psychological detachment (Sonnentag, Arbeus, Mahn, \& Fritz, 2014). Third, one study found that all participants, both compulsive and non-compulsive workers, ruminated less about work during their vacation (de Bloom et al., 2014). Importantly, this effect persisted two weeks after returning to work. Obviously, during and after a vacation people have higher levels of energetic psychological resources available, and these resources seem to act as a buffer against rumination, even when demands of the job are present again.

Altogether, it seems appropriate to assume that particularly the combination of depleted energetic resources and high work demands functions as a breeding ground for ruminative thoughts. Exhausted individuals need to raise the level of subjective effort to meet work demands, and their lack of energetic resources makes work-related goals more difficult to attain (Meijman \& Mulder, 1998). These discrepancies in goal attainment, in turn, instigate ruminative thoughts (Martin \& Tesser, 1996). The view that emphasizes the availability of energy resources is supported especially by the vacation study mentioned above (de Bloom et al., 2014). In further support, exhaustion and time pressure have been shown to interact in predicting poor psychological detachment (Sonnentag et al., 2014).

From a long-term person-centred perspective, perseverant, stressful work-related thoughts and exhaustion can be considered as inextricably interwoven components of the same deteriorating 


\section{PROFILES OF WORK-RELATED RUMINATION}

process of psychological well-being (Bergman \& Lundh, 2015; Bergman \& Trost, 2006). Applying the COR theory, this is essentially a loss cycle in terms of energy depletion and failure to restore lost energetic resources which rumination further consumes. Without proper recovery and regain of energy, short-term load reactions accumulate and become more harmful (Meijman \& Mulder, 1998; Sonnentag et al., 2010). Thus, our results concur with the notion of Querstret et al. (2016) that rumination and indicators of lack of energy may be involved in a cycle whereby one feeds the other. However, it is important to bear in mind that negative psychological states and rumination may be related because they are influenced by the same factors (Martin \& Tesser, 1996), such as workload (Zohar et al., 2003), conflicts (Volmer, 2015; Wang et al., 2013), or other negative events at work (Bono, Glomb, Shen, Kim, \& Koch, 2013). Therefore, a holistic view is needed to understand workrelated rumination at the level of the individual, in accordance with the person-centred research paradigm (Bergman et al., 2003; Bergman \& Lundh, 2015).

\section{Limitations}

This study is not without limitations. First, the main limitation relates to sample attrition which is a threat to both internal and external validity. In particular, participants reporting higher exhaustion as well as lower transformational leadership and lower conflict management were less likely to participate at T3. Concerning external validity, it is therefore very likely that our study overestimated these leadership behaviours and underestimated true exhaustion levels at $\mathrm{T} 3$, which presumably bears on levels of work-related rumination as well. It is also possible that more exhausted employees did not even respond to the first questionnaire, so that their attrition could not be analysed. In addition, attrition may relate to variables not measured in this study. To avoid further loss of information we preferred using all available data where possible. Consequently, only $72 \%, 84 \%$, and $73 \%$ of the participants in $\mathrm{T} 1-\mathrm{T} 2, \mathrm{~T} 2-\mathrm{T} 3$, and $\mathrm{T} 1-\mathrm{T} 3$, respectively, were the same individuals, due to missing data. We maintain, however, that using all available data brought our results closer to reality than handling missing data listwise (Little, 2013). 


\section{PROFILES OF WORK-RELATED RUMINATION}

Second, most participants were women, which is a further threat to external validity of the study. Although the proportion of women was only slightly higher compared to the situation in the municipal work units taking part in the study, the results may not be generalizable to men. Third, concerning analyses on the distal variables, we used posterior probabilities as the basis for classification where possible, but needed to initially rely on the most likely latent classes when calculating the change scores within the classes. Fourth, this study is subject to the method bias that derives from relying on the same rating source for all the variables. Therefore, it is in principle possible that, for example, high levels of job demands in the higher WRR classes reflect more of the compensatory effort and reactions of exhausted participants than the more objective reality of job requirements. On the other hand, it is necessary to examine subjective experiences when investigating work-related rumination. In this respect, employees themselves are the most suitable assessors of many of our focal variables. Fifth, there seems to be a conceptual contradiction in the scale we used to measure work-related rumination: one of the items concerns difficulty in relaxing after work without any reference to intrusive thoughts. Although difficulty to relax and stressful work-related thoughts are likely to co-occur, as also indicated by good internal consistency of the measure, it is possible that the nature of this item may have affected the results by the reference to psychophysiological tension.

\section{Suggestions for future studies}

On a general level, we concur with the view that work and organizational psychology would benefit from descriptive studies on change alongside predictive studies (Kelloway \& Francis, 2013), and encourage further research from different methodological approaches. A review on longitudinal predictive studies concluded that lagged effects of stressors on strain peaked at three years (Ford et al., 2014). In accordance with that, our results indicated that a two-year timeframe is useful for detecting steady change trends in subgroups of data. 


\section{PROFILES OF WORK-RELATED RUMINATION}

Furthermore, the results of this study indicated that it could be useful to utilize the organizational justice literature in studies of work-related rumination. In particular, work-related rumination could be triggered by the experience of threat related to injustice especially when an individual is in a state of depleted psychological resources (Ford \& Huang, 2014). Additionally, researchers could ask participants about the contents of their perseverative thoughts, for example, whether the thoughts relate to work tasks, organization of work, co-workers, or supervisors. While the measure in our study was not solely limited to intrusive thoughts, we recommend that future research pays closer attention to the questionnaire items in measuring work-related rumination. In order to preserve conceptual clarity, it would be better if the measurement of the construct focused on intrusive thoughts and excluded affect, tension or lack of relaxation. Additionally, the degree to which exhaustion and work-related rumination are intertwined at the level of the individual deserves further attention in empirical studies and from a theoretical point of view.

More generally, understanding the role of leadership in long-term occupational well-being among employees is a worthwhile goal. However, to realize what happens between leaders and employees and how the influence of leadership comes about, their interactions could be also investigated in experience sampling designs. Thus far these types of studies have demonstrated that positive and negative work events have effects on employee mood, stress, and difficulty in detaching from work, with negative events showing stronger effects than positive (Bono et al., 2013; Miner, Glomb, \& Hulin, 2005; Volmer, 2015; Wang et al., 2013).

\section{Practical implications}

Supervisors are in a central and influential position in employees' work-related thinking, particularly in times of stress and high job demands. Our study supports the view that high job demands, implying more unfinished work-related goals, and disrespectful supervisor behaviours specifically provoke work-related rumination. Our results further highlight that it is not only the amount of work that matters in this regard but cognitively and particularly emotionally burdening 


\section{PROFILES OF WORK-RELATED RUMINATION}

aspects of work make it difficult to switch off from work-related problems. We therefore emphasize that organizations and supervisors should be aware that high work demands continue to influence on employees even when they are not actively working, and in order to protect psychological recovery and long-term workability, take this into account in work plans. In addition, we can see value of supervisors clearly and explicitly encouraging their employees to leave stressful work issues aside during off-job time. Further, supervisors act as an example. Therefore they should restrain their own communication to employees during non-work time and show that is acceptable to allocate proper time for private life and recovery (Koch \& Binnewies, 2015). Concerning supervisors, however, it is most important according to our results that they treat their employees fairly, equally, and with respect. In particular, they should refrain from abusive supervision behaviours. Further, supervisors should take an active role in solving conflicts among their employees. Thus, our findings concur with earlier studies showing that alongside work demands, particularly social conflicts instigate rumination and impair detachment from work (Bono et al., 2013; Volmer, 2015; Wang et al., 2013; Wendsche \& Lohmann-Haislah, 2017). Moreover, from the viewpoint of employees themselves, high ruminators may benefit from making a plan on how to proceed with unfulfilled goals (Smit \& Barber, 2016), cognitive-behavioural intervention (Querstret et al., 2016), or simple every-day strategies that helped participants in a recovery intervention to disengage from work (Hahn, Binnewies, Sonnentag, \& Mojza, 2011). 


\section{References}

Alimo-Metcalfe, B. (2013). A critical review of leadership theory. In H. S. Leonard, R. Lewis, A. M. Freedman, \& J. Passmore (Eds.), The Wiley-Blackwell handbook of the psychology of leadership, change, and organizational development (pp. 15-47). Chichester, UK: John Wiley \& Sons, Ltd.

Asparouhov, T., \& Muthén, B. (2014). Auxiliary variables in mixture modeling: Using the BCH method in Mplus to estimate a distal outcome model and an arbitrary second model. Web note 21. Retrieved from: https://www.statmodel.com/examples/webnotes/webnote21.pdf Austin, J. T., \& Vancouver, J. B. (1996). Goal constructs in psychology: Structure, process, and content. Psychological Bulletin, 120(3), 338-375. doi:10.1037/0033-2909.120.3.338

Bakker, A. B., \& Demerouti, E. (2007). The Job Demands-Resources Model: State of the art. Journal of Managerial Psychology, 22(3), 309-328. doi:10.1108/02683940710733115

Bass, B. M. (1985). Leadership and performance beyond expectations. New York, NY: Free Press. Bergman, L. R., \& Lundh, L-G. (2015). Introduction: The person-oriented approach: Roots and roads to the future. Journal for Person-Oriented Research, 1(1-2), 1-6. doi:10.17505/jpor.2015.01 Bergman, L. R., Magnusson, D., \& El-Khouri, B. M. (2003). Studying individual development in an interindividual context: a person-oriented approach. Mahwah, NJ: Lawrence Erlbaum Associates.

Bergman, L. R., \& Trost, K. (2006). The person-oriented versus the variable-oriented approach: Are they complementary, opposites, or exploring different worlds? Merrill-Palmer Quarterly, 52(3), $601-632$.

Berset, M., Elfering, A., Lüthy, S., Lüthi, S., \& Semmer, N. K. (2011). Work stressors and impaired sleep: Rumination as a mediator. Stress and Health, 27(2), 71-82. doi:10.1002/smi.1337

Bono, J. E., Glomb, T. M., Shen, W., Kim, E., \& Koch, A. J. (2013). Building positive resources: Effects of positive events and positive reflection on work stress and health. Academy of Management Journal, 56(6), 1601-1627. doi: 10.5465/amj.2011.0272

Brosschot, J. F., Gerin, W., \& Thayer, J. F. (2006). The perseverative cognition hypothesis: A review of worry, prolonged stress-related physiological activation, and health. Journal of Psychosomatic Research, 60(2), 113-124. doi:10.1016/j.jpsychores.2005.06.074 


\section{PROFILES OF WORK-RELATED RUMINATION}

Brown, D. J., \& Keeping, L. M. (2005). Elaborating the construct of transformational leadership: The role of affect. The Leadership Quarterly, 16(2), 245-272. doi:10.1016/j.leaqua.2005.01.003

Carless, S. A., Wearing, A. J., \& Mann, L. (2000). A short measure of transformational leadership. Journal of Business and Psychology, 14(3), 389-405. doi:10.1023/A:1022991115523

Carver, C.S. (1996). Goal engagement and the human experience. In R. S. Wyer (Ed.), Ruminative thoughts: Advances in social cognition (Vol. 9, pp. 49-61). Mahwah, NJ: Lawrence Erlbaum Associates.

Colquitt, J. A., Scott, B. A., Rodell, J. B., Long, D. M., Zapata, C. P., Conlon, D. E., \& Wesson, M. J. (2013). Justice at the millennium, a decade later: A meta-analytic test of social exchange and affect-based perspectives. Journal of Applied Psychology, 98(2), 199-236. doi:10.1037/a0031757

Cropley, M., \& Purvis, L. J. M. (2003). Job strain and rumination about work issues during leisure time: A diary study. European Journal of Work \& Organizational Psychology, 12(3), 195-207. doi:10.1080/13594320344000093

Cropley, M., Rydstedt, L.W., Devereux, J.J., Middleton, B. (2015). The relationship between workrelated rumination and evening and morning salivary cortisol secretion. Stress \& Health, 31(2), 150-157. doi: 10.1002/smi.2538

Cropley, M. \& Zijlstra, R. F. (2011). Work and rumination. In J. Langan-Fox \& C. L. Cooper (Eds.), Handbook of stress in the occupations (pp. 487-502). Cheltenham, UK: Edward Elgar Publishing, Ltd.

Dallner, M., Elo, A., Gamberale, F., Hottinen, V., Knardahl, S., Lindström, K., Skogstad, A., \& Ørhede, E. (2000). Validation of the General Nordic Questionnaire (QPSNordic) for psychological and social factors at work. Nord 2000:12. Copenhagen: Nordic Council of Ministers.

de Bloom, J., Radstaak, M., \& Geurts, S. (2014). Vacation effects on behaviour, cognition and emotions of compulsive and non-compulsive workers: Do obsessive workers go 'cold turkey'? Stress \& Health, 30(3), 232-243. doi:10.1002/smi.2600

de Jonge, J., Le Blanc, P.M., Peeters, M.C., \& Noordam, H. (2008). Emotional job demands and the role of matching job resources: A cross-sectional survey study among health care workers. International Journal of Nursing Studies 45(10), 1460-1469. doi:10.1016/j.ijnurstu.2007.11.002 


\section{PROFILES OF WORK-RELATED RUMINATION}

Flaxman, P. E., Ménard, J., Bond, F. W., \& Kinman, G. (2012). Academics' experiences of a respite from work: Effects of self-critical perfectionism and perseverative cognition on postrespite wellbeing. Journal of Applied Psychology, 97(4), 854-865. doi: 10.1037/a0028055

Ford, M. T., \& Huang, J. (2014). The health consequences of organizational injustice: Why do they exist and what can be done? In S. Leka and R. R. Sinclair (Eds.), Contemporary Occupational Health Psychology, Vol. 3 (pp. 35-50). Chichester, UK: John Wiley and Sons, Ltd.

Ford, M. T., Matthews, R. A., Wooldridge, J. D., Mishra, V., Kakar, U. M., \& Strahan, S. R. (2014). How do occupational stressor-strain effects vary with time? A review and meta-analysis of the relevance of time lags in longitudinal studies. Work \& Stress, 28(1), 9-30. doi: $10.1080 / 02678373.2013 .877096$

Fritz, C., \& Sonnentag, S. (2005). Recovery, health, and job performance: Effects of weekend experiences. Journal of Occupational Health Psychology, 10(3), 187-199. doi: 10.1037/10768998.10.3.187

Geurts, S. A. E., \& Sonnentag, S. (2006). Recovery as an explanatory mechanism in the relation between acute stress reactions and chronic health impairment. Scandinavian Journal of Work, Environment and Health, 32(6), 482-492. doi:10.5271/sjweh.1053

Hahn, V. C., Binnewies, C., Sonnentag, S., \& Mojza, E. J. (2011). Learning how to recover from job stress: Effects of a recovery training program on recovery, recovery-related self-efficacy and well-being. Journal of Occupational Health Psychology, 16(2), 202-216. doi: 10.1037/a0022169 Halbesleben, J. R. B. (2006). Sources of social support and burnout: A meta-analytic test of the conservation of resources model. Journal of Applied Psychology, 91(5), 1134-1145. doi: 10.1037/0021-9010.91.5.1134

Hansbrough, T. K., Lord, R. G., \& Schyns, B. (2015). Reconsidering the accuracy of follower leadership ratings. Leadership Quarterly, 26(2), 220-237. doi:10.1016/j.leaqua.2014.11.006 Harms, P. D., Credé, M., Tynan, M., Leon, M., \& Jeung, W. (2017). Leadership and stress: A metaanalytic review. The Leadership Quarterly, 28(1), 178-194. doi:10.1016/j.leaqua.2016.10.006

Hobfoll, S. E. (1989). Conservation of resources: A new attempt at conceptualizing stress. American Psychologist, 44(3), 513-524. doi:10.1037/0003-066X.44.3.513 


\section{PROFILES OF WORK-RELATED RUMINATION}

Hobfoll, S. E. (2001). The influence of culture, community, and the nested-self in the stress process: Advancing conservation of resources theory. Applied Psychology: An International Review, 50(3), 337-421. doi:10.1111/1464-0597.00062

Hyde, M., Jäppinen, P., Theorell, T., \& Oxenstierna, G. (2006). Workplace conflict resolution and the health of employees in the Swedish and Finnish units of an industrial company. Social Science \& Medicine, 63(8), 2218-2227. doi:10.1016/j.socscimed.2006.05.002

Judge, T. A., \& Piccolo, R. F. (2004). Transformational and transactional leadership: A metaanalytic test of their relative validity. Journal of Applied Psychology, 89(5), 755-768. doi:10.1037/0021-9010.89.5.755

Kelloway, E. K., \& Francis, L. (2013). Longitudinal research and data analysis. In L. E. Tetrick, M. Wang, \& R. R. Sinclair (Eds.). Research methods in occupational health psychology: Measurement, design and data analysis (pp. 374-393). New York, NY: Routledge.

Kalimo, R., Hakanen, J., \& Toppinen-Tanner, S. (2006). Maslachin yleinen työuupumuksen arviointimenetelmä MBI-GS [Finnish test manual for the Maslach Burnout Inventory General Survey]. Helsinki: Finnish Institute of Occupational Health.

Kinnunen, U., Feldt, T., Siltaloppi, M., \& Sonnentag, S. (2011). Job demands-resources model in the context of recovery: Testing recovery experiences as mediators. European Journal of Work and Organizational Psychology, 20(6), 805-832. doi:10.1080/1359432X.2010.524411

Koch, A. R., \& Binnewies, C. (2015). Setting a good example: Supervisors as work-life-friendly role models within the context of boundary management. Journal of Occupational Health Psychology, 20(1), 82-92. doi:10.1037/a0037890

Laursen, B., \& Hoff, E. (2006). Person-centered and variable-centered approaches to longitudinal data. Merrill-Palmer Quarterly, 52(3), 377-389. doi:10.1353/mpq.2006.0029

Little, T. D. (2013). Longitudinal structural equation modelling. New York, NY: Guilford Press. Lubke, G. H., \& Muthén, B. (2005). Investigating population heterogeneity with factor mixture models. Psychological Methods, 10(1), 21-39. doi:10.1037/1082-989X.10.1.21

Martin, L. L., \& Tesser, A. (1996). Some ruminative thoughts. In R. S. Wyer (Ed.), Ruminative thoughts: Advances in social cognition (Vol. 9, pp. 1-47). Mahwah, NJ: Lawrence Erlbaum Associates. 


\section{PROFILES OF WORK-RELATED RUMINATION}

Maslach, C., Schaufeli, W. B., \& Leiter, M. P. (2001). Job burnout. Annual Review of Psychology, 52(1), 397-422. doi:10.1146/annurev.psych.52.1.397

Meier, L. L., Cho, E., \& Dumani, S. (2016). The effect of positive work reflection during leisure time on affective well-being: Results from three diary studies. Journal of Organizational Behavior, 37(2), 255-278. doi:10.1002/job.2039

Meijman, T. F., \& Mulder, G. (1998). Psychological aspects of workload. In P. J. D. Drenth \& H. Thierry (Eds.), Handbook of work and organizational psychology, vol. 2: Work psychology (pp. 533). Hove, UK: Psychology Press.

Miner, A. G., Glomb, T. M., \& Hulin, C. L. (2005). Experience sampling mood and its correlates at work. Journal of Organizational and Occupational Psychology, 78(2), 171-193. doi:10.1348/096317905X40105

Mitchell, M. S., \& Ambrose, M. L. (2007). Abusive supervision and workplace deviance and the moderating effects of negative reciprocity beliefs. Journal of Applied Psychology, 92(4), 11591168. doi:10.1037/0021-9010.92.4.1159

Mohr, G., Müller, A., Rigotti, T., Aycan, Z., \& Tschan, F. (2006). The assessment of psychological strain in work contexts. European Journal of Psychological Assessment, 22(3), 198-206. doi:10.1027/1015-5759.22.3.198

Montano, D. (2016). Supervisor behavior and its associations with employees' health in Europe. International Archives of Occupational and Environmental Health, 89(2), 289-298. doi:10.1007/s00420-015-1072-8

Muthén, B. O. (1998-2004). Mplus Technical Appendices. Los Angeles, CA: Muthén \& Muthén. Retrieved from: https://www.statmodel.com/download/techappen.pdf

Muthén, L. K., \& Muthén, B. O. (1998-2012). Mplus user's guide (7th ed.). Los Angeles, CA: Muthén \& Muthén.

Nylund, K. L., Asparouhov, T., \& Muthén, B. (2007). Deciding on the number of classes in latent class analysis and growth mixture modeling: A Monte Carlo simulation study. Structural Equation Modeling, 14(4), 535-569. doi:10.1080/10705510701575396

Oosthuizen, J., Mostert, K., \& Koekemoer, F. E. (2011). Job characteristics, work-nonwork interference and the role of recovery strategies amongst employees in a tertiary institution. $S A$ Journal of Human Resource Management, 9(1), 1-15. doi:org/10.4102/sajhrm.v9i1.356 


\section{PROFILES OF WORK-RELATED RUMINATION}

Ottaviani, C., Thayer, J. F., Verkuil, B., Lonigro, A., Medea, B., Couyoumdjian, A., \& Brosschot, J. F. (2016). Physiological concomitants of perseverative cognition: A systematic review and metaanalysis. Psychological Bulletin, 142(3), 231-259. doi:10.1037/bul0000036

Pejtersen, J. H., Kristensen, T. S., Borg, V., \& Bjorner, J. B. (2010). The second version of the Copenhagen Psychosocial Questionnaire. Scandinavian Journal of Public Health, 38(3), 8-24. doi:10.1177/1403494809349858

Perko, K., Kinnunen, U., \& Feldt, T. (2014). Transformational leadership and depressive symptoms among employees: Mediating factors. Leadership \& Organization Development Journal, 35(4), 286-304. doi:10.1108/LODJ-07-2012-0082

Perko, K., Kinnunen, U., Tolvanen, A., \& Feldt, T. (2016). Investigating occupational well-being and leadership from a person-centred longitudinal approach: Congruence of well-being and perceived leadership. European Journal of Work and Organizational Psychology 25(1), 105-119. doi:10.1080/1359432X.2015.1011136

Querstret, D., \& Cropley, M. (2012). Exploring the relationship between work-related rumination, sleep quality, and work-related fatigue. Journal of Occupational Health Psychology, 17(3), 341353. doi: $10.1037 / \mathrm{a} 0028552$

Querstret, D., Cropley, M., Kruger, P., \& Heron, R. (2016). Assessing the effect of a cognitive behaviour therapy (CBT)-based workshop on work-related rumination, fatigue, and sleep. European Journal of Work and Organizational Psychology, 25(1), 50-67.

doi:10.1080/1359432X.2015.1015516

Radstaak, M., Geurts, S. A., Beckers, D. G., Brosschot, J. F., \& Kompier, M. A. (2014). Work stressors, perseverative cognition and objective sleep quality: A longitudinal study among Dutch helicopter emergency medical service (HEMS) pilots. Journal of Occupational Health 56(6), 469477. doi:10.1539/joh.14-0118-OA

Robbins, J. M., Ford, M. T., \& Tetrick, L. E. (2012). Perceived unfairness and employee health: A meta-analytic integration. Journal of Applied Psychology, 97(2), 235-272. doi:10.1037/a0025408

Schyns, B., \& Schilling, J. (2013). How bad are the effects of bad leaders? A meta-analysis of destructive leadership and its outcomes. Leadership Quarterly, 24(1), 138-158. doi:

10.1016/j.leaqua.2012.09.001 


\section{PROFILES OF WORK-RELATED RUMINATION}

Skakon, J., Nielsen, K., Borg, V., \& Guzman, J. (2010). Are leaders' well-being, behaviours and style associated with the affective well-being of their employees? A systematic review of three decades of research. Work \& Stress, 24(2), 107-139. doi:10.1080/02678373.2010.495262

Smit, B. W., \& Barber, L. K. (2016). Psychologically detaching despite high workloads: The role of attentional processes. Journal of Occupational Health Psychology, 21(4), 432-442. doi:10.1037/ocp0000019

Sonnentag, S., Arbeus, H., Mahn, C., \& Fritz, C. (2014). Exhaustion and lack of psychological detachment from work during off-job time: Moderator effects of time pressure and leisure experiences. Journal of Occupational Health Psychology, 19(2), 206-216. doi: 10.1037/a0035760

Sonnentag, S., Binnewies, C., \& Mojza, E. J. (2010). Staying well and engaged when demands are high: The role of psychological detachment. Journal of Applied Psychology, 95, 965-976. doi: $10.1037 / \mathrm{a} 0020032$

Sonnentag, S., \& Fritz, C. (2015). Recovery from job stress: The stressor-detachment model as an integrative framework. Journal of Organizational Behavior, 36(S1), S72-S103. doi:10.1002/job.1924

Söderström, M., Jeding, K., Ekstedt, M., Perski, A., \& Åkerstedt, T. (2012). Insufficient sleep predicts clinical burnout. Journal of Occupational Health Psychology, 17(2), 175-183. doi:10.1037/a0027518

Spector, P. E., \& Jex, S. M. (1998). Development of four self-report measures of job stressors and strain: Interpersonal Conflict at Work Scale, Organizational Constraints Scale, Quantitative Workload Inventory, and Physical Symptoms Inventory. Journal of Occupational Health Psychology, 3(4), 356-367.

Syrek, C. J., \& Antoni, C. H. (2014). Unfinished tasks foster rumination and impair sleeping particularly if leaders have high performance expectations. Journal of Occupational Health Psychology, 19(4), 490-499. doi:10.1037/a0037127

Syrek, C. J., Apostel, E., \& Antoni, C. H. (2013). Stress in highly demanding IT jobs: Transformational leadership moderates the impact of time pressure on exhaustion and work-life balance. Journal of Occupational Health Psychology, 18(3), 252-261. doi: 10.1037/a0033085 Syrek, C. J., Weigelt, O., Peifer, C., \& Antoni, C. H. (2017). Zeigarnik's sleepless nights: How unfinished tasks at the end of the week impair employee sleep on the weekend through rumination. Journal of Occupational Health Psychology, 22(2), 225-238. doi:10.1037/ocp0000031 


\section{PROFILES OF WORK-RELATED RUMINATION}

Taris, T., \& Kompier, M. (2014). Cause and effect: Optimizing the designs of longitudinal studies in occupational health psychology. Editorial. Work \& Stress, 28(1), 1-8.

doi:10.1080/02678373.2014.878494

Tepper, B. J. (2000). Consequences of abusive supervision. Academy of Management Journal, 43, 178-190. doi:10.2307/1556375

Tolvanen, A. (2007). Latent growth mixture modeling: A simulation study (Doctoral dissertation, University of Jyväskylä, Finland). Retrieved from http://urn.fi/URN:ISBN:951-39-2971-8

Van Laethem, M., Beckers, D. G., Kompier, M. A., Kecklund, G., van den Bossche, S. N., \& Geurts, S. A. (2015). Bidirectional relations between work-related stress, sleep quality and perseverative cognition. Journal of Psychosomatic Research, 79(5), 391-398.

doi:10.1016/j.jpsychores.2015.08.011

Vincent, S. (2012). Analyseinstrument für gesundheits-und entwicklungsförderliches

Führungsverhalten: Eine Validierungsstudie. [An instrument for the measurement of health and development promoting leadership behavior: A validation study.] Zeitschrift für Arbeitswissenschaft, 66(1), 38-57.

Volmer, J. (2015). Followers' daily reactions to social conflicts with supervisors: The moderating role of core self-evaluations and procedural justice perceptions. The Leadership Quarterly, 26(5), 719-731. doi:10.1016/j.leaqua.2015.01.005

Wang, M., Liu, S., Liao, H., Gong, Y., Kammeyer-Mueller, J., \& Shi, J. (2013). Can’t get it out of my mind: Employee rumination after customer mistreatment and negative mood in the next morning. Journal of Applied Psychology, 98(6), 989-1004. doi:10.1037/a0033656

Way, K. A., Jimmieson, N. L., \& Bordia, P. (2014). Supervisor conflict management, justice, and strain: Multilevel relationships. Journal of Managerial Psychology, 29(8), 1044-1063. doi:10.1108/JMP-04-2012-0120

Wendsche, J., \& Lohmann-Haislah, A. (2017). A meta-analysis on antecedents and outcomes of detachment from work. Frontiers in Psychology, 7, 2072. doi:10.3389/fpsyg.2016.02072

Zijlstra, F. R., Cropley, M., \& Rydstedt, L.W. (2014). From recovery to regulation: An attempt to reconceptualize 'recovery from work'. Stress \& Health, 30(3), 244-252. doi:10.1002/smi.2604 


\section{PROFILES OF WORK-RELATED RUMINATION}

Zohar, D., Tzischinski, O., \& Epstein, R. (2003). Effects of energy availability on immediate and delayed emotional reactions to work events. Journal of Applied Psychology, 88(6), 1082-1093. doi: 10.1037/0021-9010.88.6.1082 


\section{PROFILES OF WORK-RELATED RUMINATION}

Table 1. Correlations of the study variables at T1 and T1-T3.

$\begin{array}{lllllllll}1 & 2 & 3 & 4 & 5 & 6 & 7 & 8 & 9\end{array}$

\begin{tabular}{|c|c|c|c|c|c|c|c|c|c|}
\hline 1 Work-related rumination & $.65 * * *$ & $.22 * * *$ & $.23 * * *$ & $.30 * * *$ & -.11 & $-.22 * * *$ & $-.15^{*}$ & $.16^{*}$ & $.26^{* * *}$ \\
\hline 2 Workload & $.30 * * *$ & $.61 * * *$ & $.28 * * *$ & $.25 * * *$ & .03 & -.04 & -.03 & .01 & $.17 * *$ \\
\hline 3 Cognitive demands & $.25^{* * *}$ & $.30 * * *$ & $.79 * * *$ & $.66^{* * *}$ & $.15^{*}$ & .05 & .04 & .04 & -.01 \\
\hline 4 Emotional demands & $.35 * * *$ & $.31 * * *$ & $.65 * * *$ & $.74 * * *$ & .02 & $-.14^{*}$ & -.08 & $.16^{* *}$ & $.14^{*}$ \\
\hline 5 Transform. leadership & $-.11 * *$ & -.01 & $.16^{* * *}$ & $.10 *$ & $.56 * * *$ & $.54 * * *$ & $.44 * * *$ & $-.30 * * *$ & -.06 \\
\hline 6 Supervisor fairness & $-.17 * * *$ & -.05 & $.10^{*}$ & -.02 & $.68 * * *$ & $.55 * * *$ & $.36 * * *$ & $-.29 * * *$ & $-.15^{*}$ \\
\hline 7 Conflict management & $-.13 * *$ & -.08 & $.16^{* * *}$ & .04 & $.72 * * *$ & $.66^{* * *}$ & $.56 * * *$ & $-.35 * * *$ & $-.14 *$ \\
\hline 8 Abusive supervision & $.15^{* * *}$ & .06 & .01 & .08 & $-.43 * * *$ & $-.54 * * *$ & $-.51 * * *$ & $.56^{* * *}$ & .12 \\
\hline 9 Exhaustion & $.51^{* * *}$ & $.38 * * *$ & .04 & $.24 * * *$ & $-.21 * * *$ & $-.26 * * *$ & $-.31 * * *$ & $.20 * * *$ & $.54 * * *$ \\
\hline
\end{tabular}

Note. T1 correlations $(N=544-554)$ below the diagonal. T1-T3 correlations $(N=254-258)$ above the diagonal (autocorrelations on the diagonal).

T1-T3 correlations for leadership were $.63 * * *-.70 * * *$ when only participants who rated the same leader across time were included $(n=213)$.

$* p<.05 . * * p<.01 . * * * p<.001$. 


\section{PROFILES OF WORK-RELATED RUMINATION}

Table 2. Fit indices for factor mixture models of work-related rumination with different class solutions.

\begin{tabular}{llllllllll}
\hline $\begin{array}{l}\text { Number } \\
\text { of classes }\end{array}$ & \multicolumn{1}{l}{$\begin{array}{l}\text { LogL (no. of } \\
\text { free parameters) }\end{array}$} & AIC & BIC & Adj. BIC & VLMR & LMR & BLRT & likely latent class membership & Entropy \\
\hline 1 & $-1992.980(7)$ & 3999.960 & 4031.024 & 4008.800 & - & - & - & 625 \\
2 & $-1961.569(11)$ & 3945.138 & 3993.953 & 3959.030 & .1091 & .1170 & .0000 & 422,203 & .678 \\
3 & $-1943.084(15)$ & 3916.169 & 3982.735 & 3935.112 & $\mathbf{. 0 1 1 8}$ & $\mathbf{. 0 1 3 5}$ & .0000 & $183,38,404$ & .678 \\
4 & $-1920.571(19)$ & 3879.141 & 3963.458 & 3903.136 & .4847 & .4949 & .0000 & $309,163,62,91$ & .707 \\
5 & $-1903.669(23)$ & 3853.339 & $\mathbf{3 9 5 5 . 4 0 7}$ & 3882.385 & .1129 & .1181 & .0000 & $308,17,44,84,172$ & .714 \\
6 & $-1893.239(27)$ & 3840.477 & 3960.296 & 3874.575 & $\mathbf{. 0 1 5 1}$ & $\mathbf{. 0 1 6 8}$ & $\mathbf{. 0 1 0 0}$ & $42,175,302,17,4,85$ &. $\mathbf{7 3 5}$ \\
7 & $\mathbf{- 1 8 8 6 . 1 0 2 ( 3 1 )}$ & $\mathbf{3 8 3 4 . 2 0 4}$ & 3971.775 & $\mathbf{3 8 7 3 . 3 5 4}$ & .6977 & .7058 & .0600 & $19,63,128,44,48,265,58$ & .692 \\
\hline
\end{tabular}

Note. Figures indicating the statistically most favourable class solution are in bold. Regarding the Akaike's Information Criteria (AIC), Bayesian Information Criterion (BIC), and sample-size adjusted BIC (Adj. BIC), the lowest value indicates the best solution. The Vuong-Lo-Mendell-

Rubin likelihood ratio test (VLMR), Lo-Mendel-Rubin likelihood ratio test (LMR), and (parametric) bootstrapped likelihood ratio test (BLRT) assess the improvement in model fit when the number of latent classes increases by one. The $p$-value indicates whether the improvement in model fit is significant for the inclusion of one more class. Concerning classification quality (entropy and average posterior probabilities for most likely latent class membership), values close to 1 indicate clear classification (Muthén, 1998-2004). 


\section{PROFILES OF WORK-RELATED RUMINATION}

Table 3. Mean values of the study variables at each measurement wave within the latent classes of work-related rumination and mean level differences between the latent classes at $\mathrm{T} 1$ and $\mathrm{T} 3$.

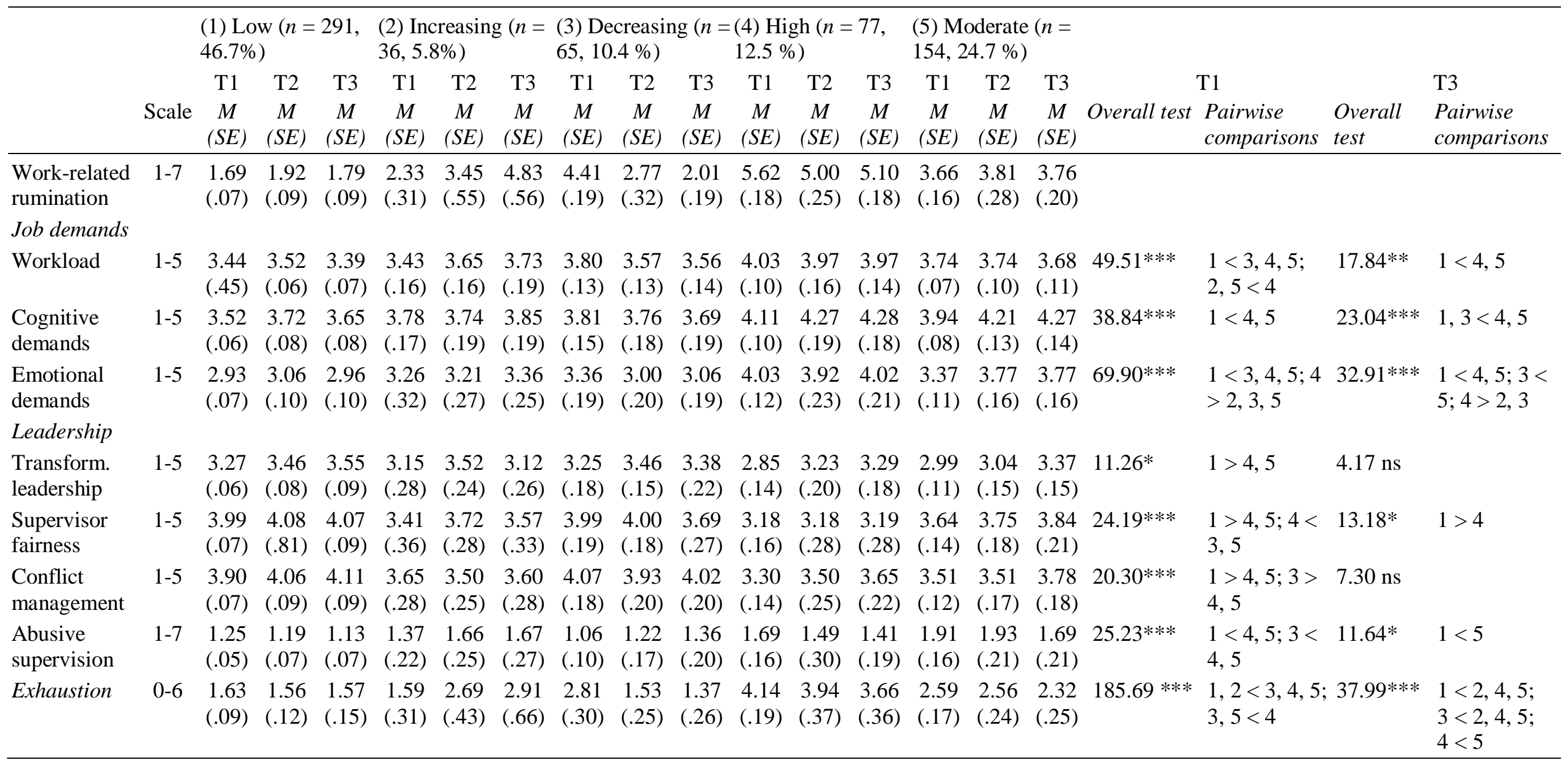




\section{PROFILES OF WORK-RELATED RUMINATION}

Table 4. Changes in job demands, leadership and exhaustion within the latent classes on workrelated rumination in $\mathrm{T} 1-\mathrm{T} 3$.

\begin{tabular}{|c|c|c|c|c|c|}
\hline & (1) Low WRR & $\begin{array}{l}\text { (2) Increasing } \\
\text { WRR }\end{array}$ & $\begin{array}{l}\text { (3) Decreasing } \\
\text { WRR }\end{array}$ & (4) High WRR & $\begin{array}{l}\text { (5) Moderate } \\
\text { WRR }\end{array}$ \\
\hline & Change $M(S E)$ & Change $M(S E)$ & Change $M(S E)$ & Change $M(S E)$ & Change $M(S E)$ \\
\hline \multicolumn{6}{|c|}{ C } \\
\hline Workload & $-0.10(.07)$ & $0.32(.16)$ & $-0.33(.12)^{*}$ & $-0.18(.14)$ & $-0.08(.12)$ \\
\hline Cognitive demands & $0.19(.06)^{*}$ & $0.02(.11)$ & $-0.22(.10)^{*}$ & $0.16(.10)$ & $0.15(.12)$ \\
\hline Emotional demands & $0.10(.08)$ & $0.20(.27)$ & $-0.43(.16)^{*}$ & $-0.01(.16)$ & $0.33(.17)^{*}$ \\
\hline \multicolumn{6}{|l|}{ Leadership } \\
\hline Transform. leadership & $0.22(.09)^{*}$ & $0.04(.20)$ & $0.10(.20)$ & $0.37(.21)$ & $0.19(.16)$ \\
\hline Supervisor fairness & $-0.09(.12)$ & $0.24(.27)$ & $-0.25(.24)$ & $0.10(.25)$ & $-0.07(.19)$ \\
\hline Conflict management & $0.07(.10)$ & $0.04(.23)$ & $0.02(.25)$ & $0.15(.19)$ & $-0.01(.18)$ \\
\hline Abusive supervision & $-0.08(.08)$ & $0.26(.25)$ & $0.37(.20)$ & $-0.27(.21)$ & $-0.05(.23)$ \\
\hline Exhaustion & $-0.07(.15)$ & $1.20(.36)^{* *}$ & $-1.64(.35)^{* * *}$ & $-0.38(.31)$ & $0.03(.32)$ \\
\hline
\end{tabular}

Note. Longitudinal participants in each class (based on the most likely latent class) in T1-T3 (1) $n$ $=114$, (2) $n=16$, (3) $n=27$, (4) $n=35$, (5) $n=66$, T1-T2 (1) $n=113$, (2) $n=17$, (3) $n=30$, (4) $n$ $=30$, (5) $n=72$, and in T2-T3 (1) $n=106$, (2) $n=16$, (3) $n=22$, (4) $n=24$, (5) $n=57$.

$* p<.05 . * * p<.01 . * * * p<.001$. 